\title{
Percutaneous transluminal balloon angioplasty in restenosis of coarctation of the aorta
}

\author{
J HESS, * E L MOOYAART, $\dagger$ H J BUSCH,§ A BERGSTRA, $\ddagger$ M L J LANDSMAN $\ddagger$ \\ From the Departments of * Paediatrics (Division of Paediatric Cardiology), $\nmid$ Radiology and $\ddagger$ Cardiac \\ Catheterisation, University Hospital, Groningen; and the §Department of Paediatrics (Division of Paediatric \\ Cardiology), University Hospital, Nijmegen, The Netherlands
}

SUMMARY Percutaneous transluminal balloon angioplasty was performed in five children with coarctation restenosis. After angioplasty the pressure gradient had decreased considerably in four patients. In all patients aortography showed an increase in the diameter of the lumen at the site of the restenosis. All patients were normotensive the day after angioplasty. There were no complications during or after the procedure.

Surgical repair of aortic coarctation has become a safe and successful procedure. ${ }^{1}$ Despite the use of newer techniques such as patch angioplasty, and the subclavian flap procedure, however, there is still a considerable incidence of coarctation restenosis, especially when operation has been performed in infancy. ${ }^{23}$ Reoperation in these patients is associated with a higher morbidity and mortality and with less adequate relief than primary coarctation repair. ${ }^{4}$ Recently, percutaneous transluminal angioplasty has been shown to be a promising treatment for coarctation restenosis. ${ }^{5-7}$

We present the results of percutaneous transluminal angioplasty for coarctation restenosis in five children who had had different types of primary surgical repair.

\section{Patients and methods}

Five patients, aged 1.5 to 14.3 years (mean 8.2 years) underwent cardiac catheterisation and subsequent percutaneous transluminal angioplasty because of systemic hypertension due to coarctation restenosis. Three patients had had primary coarctation repair by means of resection and end to end anastomosis,

Requests for reprints to Dr J Hess, Department of Paediatrics, University Hospital, 59 Oostersingel, 9713 EZ Groningen, The Netherlands.

Accepted for publication 14 January 1986 one by a subclavian artery flap procedure, and one by end to side anastomosis of the left subclavian artery on the descending aorta because of the local anatomical situation. The ages at primary repair ranged from 3 days to 6.2 years (mean 1.7 years). In four children angioplasty was performed under general anaesthesia.

The pressure gradients across the restenosis were measured and the cardiac indices were calculated from dye dilution curves before and 20 minutes after angioplasty. Percutaneous transluminal angioplasty was performed with Meditech balloon dilatation catheters. The diameters of the balloons that were used ranged from $8 \mathrm{~mm}$ to $18 \mathrm{~mm}$ and the size was selected according to the coarctation diameter (measured at aortography) multiplied by $2 \cdot 5$. The balloon diameter never exceeded $1.2 \times$ the diameter of the descending aorta. The dilatation catheter was positioned at the site of the restenosis over a guide wire the tip of which was advanced into the ascending aorta. Under continuous fluoroscopy the balloon was inflated to pressures of $4 \mathrm{~atm}$ with a 3:1 dilution of contrast medium.

This procedure was carried out three times. Each inflation lasted for about 10 seconds. After angioplasty the balloon catheter was withdrawn, and the tip of the guide wire was kept in the ascending aorta. A multipurpose catheter was then carefully introduced over the guide wire to the ascending aorta. This catheter was used for repeated aortography, pressure measurements, and dye sampling for calculation of the cardiac indices. 


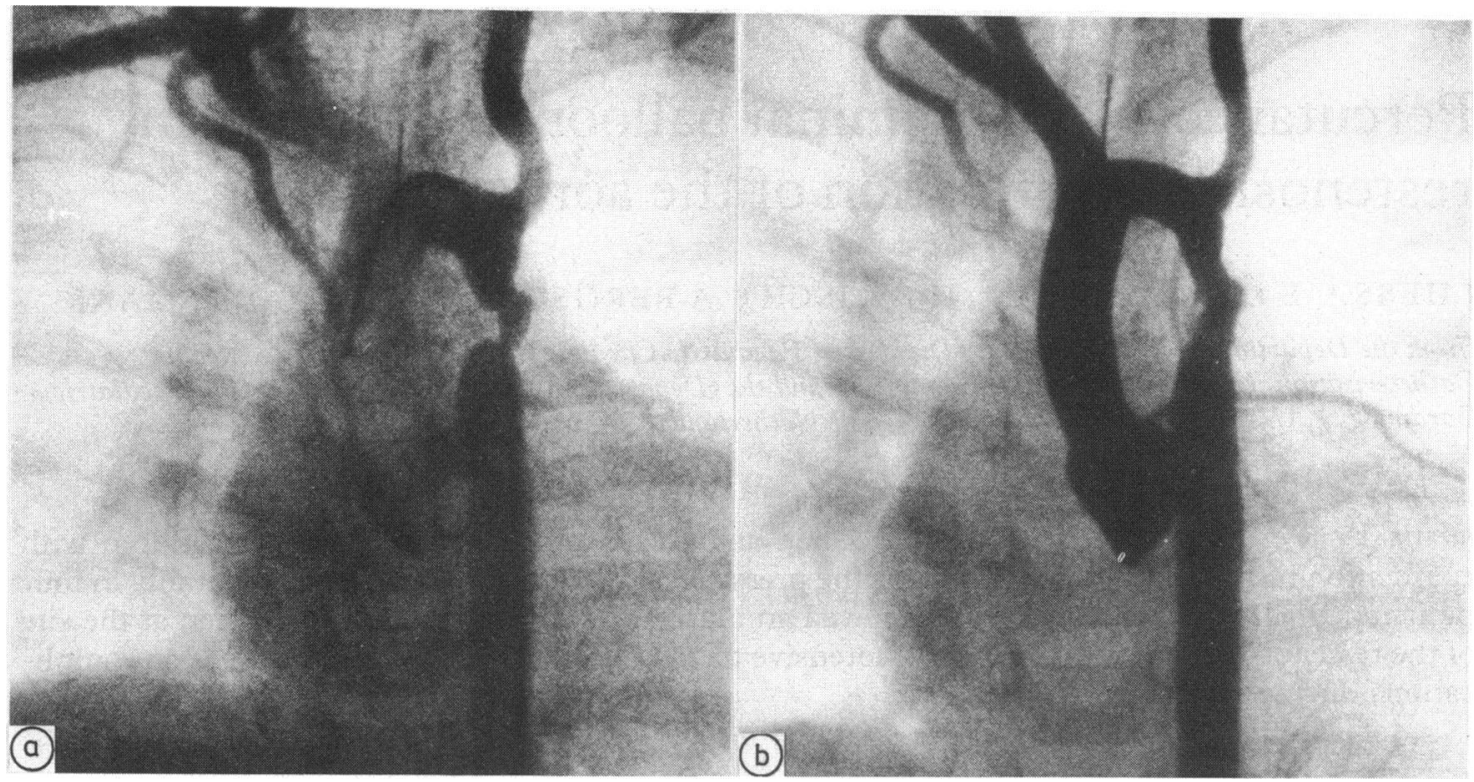

Fig. 1 Aortography before (a) and after ( $b$ ) percutaneous transluminal balloon angioplasty in a patient in whom a subclavian flap operation had been performed. There is a considerable increase of the diameter of the restenosis after angioplasty.

\section{Results}

There were no complications during or after the procedure. In three patients the balloon ruptured, but this caused no noticeable reaction.

Before angioplasty the systolic pressure gradients

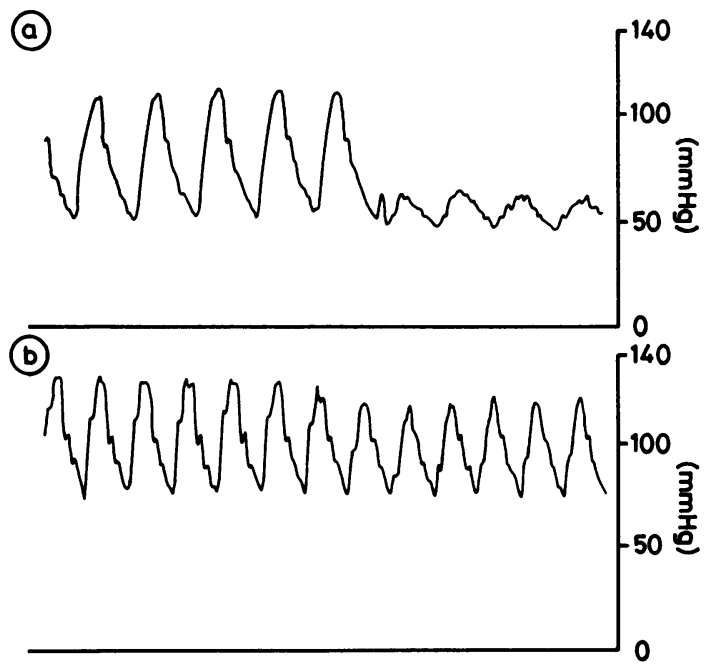

Fig. 2 Pressure withdrawal curve from the ascending to the descending aorta in the same patient before (a) and after (b) percutaneous transluminal balloon angioplasty. across the coarctation restenosis ranged from 15 to $49 \mathrm{~mm} \mathrm{Hg}$ (mean $27 \mathrm{~mm} \mathrm{Hg}$.) The cardiac indices ranged from 2.4 to $3.61 / \mathrm{min} / \mathrm{m}^{2}$ (mean $3.1 \mathrm{l} / \mathrm{min} / \mathrm{m}^{2}$ ). At aortography four patients had a circumscribed restenosis and one had a tubular narrowing. This patient had the smallest pressure gradient.

After percutaneous transluminal balloon angioplasty the systolic pressure gradients had decreased in four patients (range 5 to $21 \mathrm{~mm} \mathrm{Hg}$, mean $12.2 \mathrm{~mm} \mathrm{Hg}$ ). At aortography there was an increase of the lumen diameters of the restenosis in all patients that ranged from $25 \%$ to $89 \%$ (mean $70 \%$ ) of the diameters before angioplasty. In the patient with tubular narrowing angioplasty did not reduce the pressure gradient. Yet the angiographic appearance of this segment indicated an increase in diameter. The cardiac index after angioplasty ranged from 4.0 to $4.51 / \mathrm{min} / \mathrm{m}^{2}$ (mean $\left.4 \cdot 21 / \mathrm{min} / \mathrm{m}^{2}\right)$.

All patients were normotensive the day after angioplasty.

\section{Discussion}

Our data indicate that percutaneous transluminal angioplasty for coarctation restenosis improved all five patients. In all patients there was a substantial increase of the coarctation diameter; in four this was associated with a considerable decrease in the press- 
ure gradient. According to the criteria of Lock et al (that is the combination of a $30 \%$ or larger increase in the diameter at the restenosis and a greater than $50 \%$ fall in the gradient after dilatation) percutaneous transluminal angioplasty was successful in these four patients, and the clinical response was good. The fall in the gradient is an important determinant of the blood flow across the coarctation. All patients had a pronounced increase of the cardiac index after angioplasty, and this masks the result to a certain extent. The effect probably explains the apparently poor result in the patient with the tubular stenosis. This patient, however, had had upper body hypertension for a long time and was normotensive the day after angioplasty.

Percutaneous transluminal angioplasty has been accepted as an alternative to operation. It is a safe procedure for pulmonary valve stenosis with results that are comparable to surgery. ${ }^{8-10}$ The success rate in pulmonary branch stenosis is only $50 \%$ but angioplasty should be considered in patients in whom operation is not feasible because of the localisation and multiplicity of lesions. ${ }^{11-12}$

Valvar aortic stenosis in some cases has been reported to be amenable to angioplasty; however, no definite conclusions can yet be drawn about its possible advantages over surgical intervention. ${ }^{9}$ Although the short term benefits of angioplasty for primary aortic coarctation are known, there is concern about the long term follow up. ${ }^{5713}$ The efficacy of percutaneous transluminal angioplasty depends upon disruption of intima and part of the media of the vessel. ${ }^{14}$ This may result in areas of medial thinning. The formation of associated aneurysms has not been described but these might develop later in life. ${ }^{15}$ In the case of coarctation restenosis the presence of scar tissue should reduce or even prevent the occurrence of this complication. There has been a report of one death after percutaneous transluminal angioplasty for coarctation restenosis; however, this was not related to disruption of the vessel. ${ }^{6}$ Although follow up studies are needed to evaluate the long term results of percutaneous transluminal angioplasty for coarctation restenosis, the procedure seems to offer a relative safe and effective alternative to reoperation that may be used after all types of primary surgical repair.

\section{References}

1 Lezberg DB, Hardesty RL, Siewers RD, et al. Coarctation of the aorta in infants and children: 25 years of experience. Ann Thorac Surg 1982; 33: 159-62.

2 Hartmann AF Jr, Golding D, Hernandez A, et al. Reccurent coarctation of the aorta after successful repair in infancy. Am $\mathcal{f}$ Cardiol 1970; 25: 405-10.

3 Hesslein PS, McNamara DG, Morries MJH, Hallman GL, Cooley DA. Comparison of resection versus patch aortoplasty for repair of coarctation of aorta in infants and children. Circulation 1981; 64: 164-8.

4 Pollack P, Freed MD, Castaneda AR, Norwood WI. Reoperation for isthmic coarctation of the aorta: followup of 26 patients. Am $\mathcal{F}$ Cardiol 1983; 51: 1690-4.

5 Lock JE, Bass JL, Amplatz K, Fuhrman BP, Castaneda-Zuniga W. Balloon dilation angioplasty of aortic coarctations in infants and children. Circulation 1983; 68: 109-16.

6 Kan JS, White RI, Mitchell SE, Farmlett EJ, Donahoo JS, Gardner TJ. Treatment of restenosis of coarctation by percutaneous transluminal angioplasty. Circulation 1983; 68: 1087-94.

7 Lababidi ZA, Daskalopoulos DA, Stoeckle H. Transluminal balloon coarctation angioplasty: experience with 27 patients. Am F Cardiol 1984; 54: 1288-91.

8 Kan JS, White RI, Mitchell SE, Anderson JH, Gardner TJ. Percutaneous transluminal balloon valvuloplasty for pulmonary valve stenosis. Circulation 1984; 69: 554-60.

9 Walls JT, Lababidi Z, Curtis JJ, Silver D. Assessment of percutaneous balloon pulmonary and aortic valvuloplasty. F Thorac Cardiovasc Surg 1984; 88: 352-6.

10 Miller GAH. Balloon valvuloplasty and angioplasty in congenital heart disease. Br Heart $\mathcal{F}$ 1985; 54: 285-9.

11 Lock JE, Castaneda-Zuniga WR, Fuhrman BP, Bass JL. Balloon dilation angioplasty of hypoplastic and stenotic pulmonary arteries. Circulation 1983; 67: 962-7.

12 Rocchini AP, Kveselis D, MacDonald D, Crowdey D, Snider AR, Rosenthal A. Use of balloon angioplasty to treat peripheral pulmonary stenosis. Am $\mathcal{f}$ Cardiol 1984; 54: 1069-73.

13 Finley JP, Beaulieu RG, Nanton MA, Roy DL. Balloon catheter dilatation of coarctation of the aorta in young infants. Br Heart $\mathcal{F} 1983$; 50: 411-5.

14 Lock JE, Niemi T, Einzig S, Amplatz K, Burke B, Bass JL. Transvenous angioplasty of experimental branch pulmonary artery stenosis in newborn lambs. Circulation 1981; 64: 886-93.

15 Lock JE. Now we can dilate, should we? Am $\mathcal{f}$ Cardiol 1984; 54: 1360. 